\title{
Face recognition by hand
}

\author{
ANDREA R. KILGOUR and SUSAN J. LEDERMAN \\ Queen's University, Kingston, Ontario, Canada
}

\begin{abstract}
We investigated participants' ability to identify and represent faces by hand. In Experiment 1, participants proved surprisingly capable of identifying unfamiliar live human faces using only their sense of touch. To evaluate the contribution of geometric and material information more directly, we biased participants toward encoding faces more in terms of geometric than material properties, by varying the exploration condition. When participants explored the faces both visually and tactually, identification accuracy did not improve relative to touch alone. When participants explored masks of the faces, thereby eliminating material cues, matching accuracy declined substantially relative to tactual identification of live faces. In Experiment 2, we explored intersensory transfer of face information between vision and touch. The findings are discussed in terms of their relevance to haptic object processing and to the faceprocessing literature in general.
\end{abstract}

To date, research on haptic object processing has dealt almost exclusively with inanimate objects. Many of the early studies in this field during the 1960s and 1970s addressed the processing of geometric properties, particularly shape and size, by the haptic and visual systems (for further details, see Walk \& Pick, 1981). Such studies typically used either two-dimensional (2-D) or three-dimensional (3-D) solid nonsense forms made of some homogeneous material. They focused primarily on relative performance accuracy, inasmuch as response duration was often equated across all modality conditions. The haptic system performed quite poorly in those studies. More recent studies have investigated how well blindfolded sighted, visually impaired, and blind observers can identify common objects at the basic level, as depicted in raised line drawings. Accuracy has varied from very poor in open-set identification (e.g., Lederman, Klatzky, Chataway, \& Summers, 1990; Magee \& Kennedy, 1980) to very good with small closed sets and/or when observers were initially primed with the superordinate category represented by the drawing (e.g., as high as $88 \%$; see Heller, Calcaterra, Burson, \& Tyler, 1996). Corresponding mean response times, however, have been consistently high-for example, ranging from 30 to $71 \mathrm{sec}$ across various conditions in the Heller et al. (1996) study and up to $90 \mathrm{sec}$ or over in the Lederman et al. (1990) experiments.

In contrast, Tadoma, a method used by deaf-blind individuals to understand spoken speech by statically contact-

This research was supported by an NSERC postgraduate fellowship to A.R.K. and by an NSERC research grant to S.J.L. We thank Cheryl Hamilton for her considerable help on this project. In addition, we thank all of the people (especially Jennifer Laforce) who heroically offered their faces as living exemplars. Finally, we thank Louise Wasylkiw for her assistance in the preliminary rating work, Sue Lyon for her assistance in creating the masks, Monica Hurt for her assistance with graphics, and Kang Lee for his comments on an earlier version of this paper. Correspondence concerning this article can be addressed to S. J. Lederman, Department of Psychology, Queen's University, Kingston, ON, K7L 3N6 Canada (e-mail: lederman@psyc.queensu.ca). ing faces in real time, serves as an existence proof that the haptic system can process complex information both accurately and quickly (e.g., Norton et al., 1977). Klatzky, Lederman, and Metzger (1985) have also documented highly efficient haptic performance. They required blindfolded participants to haptically explore and identify an open set of 100 common 3 -D objects as quickly and as accurately as possible. Naming accuracy was $99 \%$, and the modal response time was only about $2 \mathrm{sec}$, indicating excellent processing efficiency by the haptic system in terms of high accuracy combined with high speed.

Klatzky et al. (1985) noted that the availability of multiple sources of information about common objects served to enhance performance. Neither nonsense objects made of a homogeneous material nor most raised-line graphics displays provide the full range of properties, and, therefore, they restrict the observer to the use of time-consuming contour-exploration heuristics, with associated constraints on spatial and temporal integration.

Lederman and Klatzky (1987) showed that with multiproperty nonsense objects, participants performed eight different highly stereotypical hand-movement patterns (exploratory procedures or EPs) — not just contour followingdepending on which property was targeted by the experimenter in a match-to-sample task. For example, they typically executed a lateral motion $\mathrm{EP}$ - a repetitive rubbing motion - when asked to attend to surface texture. Other researchers (e.g., Ballesteros, Manga, \& Reales, 1997) have also confirmed the specificity of these EPs.

Such data show that participants methodically execute different fundamental hand-movement patterns to extract information about specific object properties. When processing objects whose diversity of properties more fully complement the range of efficient information-gathering hand movements possible, the haptic system manifests considerable skill.

Human faces have not typically been treated as objects but rather as a special category (see, Farah, Wilson, Drain, 
\& Tanaka, 1998; Nachson, 1995). Nevertheless, it is not unreasonable to treat them as 3-D objects that vary in both geometric and material properties.

To date, there exists no published research that has directly investigated whether, and if so, how the haptic system processes faces. There are, however, several indirect and limited contributions to the topic of haptic face processing. Kaitz and colleagues (Kaitz, 1992; Kaitz, Lapidot, Bronner, \& Eidelman, 1992; Kaitz, Meirov, \& Landman, 1993; Kaitz, Shiri, Danzinger, Hershko, \& Eidelman, 1994) conducted several studies in which participants were required to identify their romantic partners or newborn infants solely by haptic exploration. In Kaitz's study, participants were required to identify their romantic partners by actively touching only the dorsal surface of the hands or a small area of the forehead. The romantic partner was designated the target, and he/she was to be identified from among two other foils. Kaitz found that participants could accurately perform this task $58 \%$ of the time. Although both men and women could identify their opposite-sex partners by touching the forehead (50\% and $67 \%$ success, respectively), only women were able to recognize their partners by touching the back of the hand (69\% accuracy). Kaitz concluded that men have more differentiating characteristics (particularly hair, which is a material cue) on their hands. The overall conclusion was that tactile cues are sufficiently salient to allow for recognition of a highly familiar individual.

In three subsequent studies (Kaitz et al., 1992; Kaitz et al., 1993; Kaitz et al., 1994), parturient women and fathers of newborn infants were required to haptically identify their infants, as before, from among three comparisons. In these studies, the parents were allowed to touch only the dorsal surface of the hand or the cheek. Although parents were not successful at identifying their infants with whom they had less than $1 \mathrm{~h}$ of contact ( $36 \%$ accuracy), parents did identify infants as young as 7-h old approximately $65 \%$ of the time. Participants in these experiments identified two material characteristics, texture and temperature, as the most salient diagnostic characteristics.

The Kaitz studies did not directly address whether humans are specifically able to recognize faces haptically. They demonstrated skin - as opposed to face - recognition abilities. However, these studies do provide a basis for hypothesizing that humans can do so. One would expect skin recognition to be more difficult than face recognition, given the poverty of information about the skin, as compared with the rich complexities of an entire face. Like common objects, faces vary both in their geometric structure and in their material characteristics.

Overall, the previous studies collectively demonstrate that the accuracy and speed of haptic object identification depends on the nature of the stimuli employed. When solid, planar objects of a single material are explored haptically, object identification is typically relatively poor. Identification accuracy and speed increase when more property variation, such as 3-D geometric and material variation, is provided (see Klatzky, Loomis, Lederman,
Wake, \& Fujita, 1993). Finally, the identification of familiar, living faces through haptic exploration of restricted areas is not as accurate as with unlimited exploration of common inanimate objects.

Studies of the haptic recognition of inanimate objects have highlighted a distinction between geometric and material inputs, with ramifications for their relative contributions to haptic processing and to the nature of the underlying object representations. Lederman and Klatzky (1987) emphasized the importance of this distinction, because the EPs used to extract material properties are executed more quickly and more accurately than those used to obtain information about geometric properties. Klatzky, Lederman, and Reed (1987) and Lederman, Summers, and Klatzky (1996) investigated the relative salience of material and geometric properties for haptic versus visual object processing. Their findings confirmed that haptically derived object representations strongly reflect information pertaining to material properties, in addition to geometric properties; in contrast, visually derived object representations more strongly reflect geometric information about objects. These two studies dealt with the relative importance of material and geometric properties for haptic processing and for representing unfamiliar objects, when property weighting is influenced by long-term modality-encoding biases. (A modality-encoding bias refers to one that is based on a lifetime of experience in using different modalities to encode property changes across many different objects.)

To what extent do geometric and material properties contribute to haptic processing and to the haptically derived representations of familiar objects? Lederman and Klatzky (1990, Experiment 1) determined which haptically derived object properties were most diagnostic of common-object classes at both the basic and subordinate levels of classification. According to Rosch, Mervis, Gray, Johnson, and Boyes-Braem (1976), basic categories, such as pen and glass, are those that carry the most information, possess the highest category cue validity, and are, thus, the most differentiated from one another. Objects within the same subordinate-level class, such as fountain pen and wine glass, vary perceptually to a lesser degree than do those at the basic level. Participants reported more diagnostic properties of targeted common-object classes at the basic level than at the subordinate level. Of these properties, more were geometric than material. At the subordinate level, however, participants reported more material properties as being diagnostic.

The material/geometric distinction is relevant to the present study, in that faces inherently include both geometric and material properties. We asked how geometric and material information contributes to the haptic processing and representation of faces at the subordinate level of classification, since faces are classified at that level. It can be argued that neither type of information will vary as extensively as it does with common objects classified at the basic level.

Lederman et al. (1990) observed that many of the earliest studies on haptic identification of nonsense objects fo- 
cused primarily on performance accuracy, rather than on the nature of haptic processing and encoding. Furthermore, there seemed to be an unspoken assumption that the haptic system processes information in a similar, but inferior, manner to vision. That is, haptic input is translated into a visual image and then the object is represented through the visual-processing system. They called this process the image-mediation model of haptics (Klatzky \& Lederman, 1987; Lederman \& Klatzky, 1990). Lederman et al. (1990) conducted a study to verify the image-mediation model for 2-D displays under conditions that encouraged visual mediation. Under such conditions, one might have expected individuals to utilize visual-image mediation, because this heuristic is one of the few possible when only contour information is available.

Four results of the Lederman et al. (1990) study provide support for the use of an image-mediation heuristic. One example of their results is that they found a significant, negative correlation between scores on the Vividness of Visual Imagery Questionnaire (VVIQ; Marks, 1973) and both recognition speed and accuracy. Participants who scored lower on the VVIQ (indicating high ability to use visual imagery) demonstrated higher identification accuracy and faster response times. The study's results provided empirical support for the use of an imagemediation process during the haptic exploration of raised 2-D pictures of common objects. An image-mediation heuristic helped haptic recognition when the stimuli offered only contour information; however, such assistance was limited at best (for additional discussions of image mediation and imagery in haptics, see, Révész, 1950; Cornoldi \& Vecchi, 2000).

To date, we know of no research that has investigated the use of visual mediation when 3-D multiproperty objects are haptically processed. Visual mediation may not be as useful for easy tasks, such as the classification of objects at the basic level. As noted earlier, such objects provide a range of geometric and material properties that are easily accessible for haptic processing and identification. In the present study, we investigated haptic face recognition, which is performed at the more difficult subordinate level. The use of visual mediation may therefore prove more beneficial, particularly since faces are usually identified by vision.

More generally, in two experiments, we asked three questions concerning haptic face recognition. First, how well can people identify unfamiliar live faces at the subordinate level? Second, how do people encode or represent such faces? Third, do people use visual mediation as a heuristic when processing faces haptically?

Experiment 1 served as an existence proof that people can haptically identify live unfamiliar faces at the subordinate level with surprising accuracy. Only the sense of touch was used in a haptic match-to-sample $(\mathrm{H}-\mathrm{H})$ task. In the experiment, we also considered how people represent faces explored solely by touch. To do so, we examined the nature and frequency of the features that the participants reported using to identify the initial standard faces. We further examined the contribution of geometric and material cues by deliberately biasing the participants to weight the geometric features more heavily in their representations. Finally, the participants completed the VVIQ test so that we could determine whether or not visual mediation was used.

Experiment 2 extended Experiment 1 to specifically address intermodal-matching performance. In the first of two conditions, we required participants to visually explore the standard faces and then to identify the standards haptically from among three comparisons $(\mathrm{V}-\mathrm{H})$. The second condition required participants to explore the standard faces haptically and then to identify them visually from three comparisons $(\mathrm{H}-\mathrm{V})$. We again examined three main issues: matching accuracy, the nature of the representation, and evidence for a visual-mediation process.

\section{EXPERIMENT 1}

In Experiment 1, the participants were blindfolded throughout the entire task and were required to perform a match-to-sample task with human faces as the exemplars (the $\mathrm{H}-\mathrm{H}$ condition). There were two possible contrasting predictions with respect to matching accuracy. It was not unreasonable to predict that matching accuracy would be poor. In the Kaitz et al. (1992; Kaitz et al., 1993; Kaitz et al., 1994) studies, accuracy ranged from chance to approximately $66 \%$, depending on the degree of familiarity with the exemplars. Moreover, in the present task, we required subordinate-level matching, which is a perceptually more difficult task than is basic-level matching. Thus, there was no reason to expect the same high accuracy as that shown by Klatzky et al. (1985) with common objects. On the contrary, we could argue that accuracy should be better than that in the Kaitz studies, owing to an increase in the amount of available information (the entire face, rather than a limited facial area). To the extent that we observed relatively high performance accuracy, the results should serve as an existence proof that the haptic system alone is capable of identifying a human face.

In order to assess the relative importance of geometric and material cues for haptic face processing more directly, two additional conditions were included. In one condition (VH-H), the participants were permitted to explore the standard face both haptically and visually, thereby providing more precise geometric information during the standard phase than is possible with haptics alone. However, they matched the standard to the comparison faces by using touch alone. In this way, we attempted to bias the participants toward using geometric properties to encode faces more than in the $\mathrm{H}-\mathrm{H}$ condition. At the same time, additional visual sources of information were provided about both geometric and material properties. Matching accuracy was expected to increase with respect to the $\mathrm{H}-\mathrm{H}$ condition.

In the final condition $\left(\mathrm{H}_{\text {Mask }}-\mathrm{H}_{\text {Mask }}\right)$, we also biased the participants toward geometric properties. Participants were asked to perform the same task as that in the $\mathrm{H}-\mathrm{H}$ condition; however, the exemplars were rigid masks of the same live faces as those used in the $\mathrm{H}-\mathrm{H}$ condition. These exemplars provided all the complex geometrical in- 
formation, but without the natural variation in material properties. Therefore, the results enabled us to evaluate the relative importance of material cues. If geometric properties are solely sufficient for identification, the $\mathrm{H}_{\text {Mask }}-\mathrm{H}_{\text {Mask }}$ condition should result in similar matching accuracy to that obtained with the $\mathrm{H}-\mathrm{H}$ condition. However, if material cues are critical, the removal of material variation should result in a decline in matching accuracy. The matching accuracies and the reported cues used in matching judgments were utilized to shed further light on the relative importance of geometric and material properties in encoding faces during haptic exploration.

Given the presumed difficulty of these tasks, the fact that face recognition is traditionally a visual task, and that the $\mathrm{VH}-\mathrm{H}$ condition included vision during the initial exploration, it seemed reasonable that the participants might use a matching strategy based on a visual heuristic that included a visual-mediation stage. According to the same logic, when material cues were removed in the $\mathrm{H}_{\text {Mask }}-\mathrm{H}_{\text {Mask }}$ condition, the participants would presumably focus more on geometry, again possibly encouraging the use of a visualmediation process. To the extent that visual mediation was adopted, we expected to find a correlation between obtained VVIQ scores and matching accuracy.

\section{Method}

\section{Participants}

Ninety undergraduate students (22 men and 68 women, mean age, 19.6 years, $S D=2.4$ ) participated in the present study in partial fulfillment of an introductory psychology course credit. Testing procedures met with the standards of the Ethics Review Committee in the Department of Psychology at Queen's University.

\section{Materials}

The VVIQ (Marks, 1973) was administered to each participant. This questionnaire is a measure of visual-imagery ability in which participants are presented with four different scenarios. The VVIQ has a minimum score of 16 (highest imaging ability) and a maximum score of 80 (lowest imaging ability). Manual exploration of the exemplar faces by each participant was recorded with a Quasar S-VHS video camera. A portable stereo system with headphones was used to present white noise to the participants.

Selection of face exemplars. Forty-seven women volunteered to be potential face exemplars for this study. Two photographs, one fullfront face and one profile face, were taken of each individual with a Samsung-AF camera. Each photograph was taken at a distance of 3 feet under florescent lighting.

Three independent raters viewed all the photographs and visually categorized each potential exemplar's facial features. For example, an individual was categorized as having a round, square, oval, or heartshaped face. In addition, the raters were asked to view all the photographs presented together and to subjectively group potential exemplars on the basis of visual similarity. All 47 rating sheets were categorized into four groups according to the overall shape-of-face ratings. These four groups were further subdivided according to the ratings of the similarity of the nose, chin, and forehead characteristics, resulting in eight possible groups composed of 31 potential face exemplars. On the basis of the rating sheets and the subjective groupings, 16 potential face exemplars were discarded from the pool.

Two independent raters then categorized all remaining potential face exemplars (31) on the basis of a set of designated tactual characteristics. The raters were blindfolded and were unaware of both the identity of each potential face exemplar and the assigned visual rating.
Again, potential face exemplars were grouped according to similarity of tactual characteristics.

The visual and tactual ratings were compared. Potential face exemplars that were grouped together on the basis of both visual and tactual similarity were included in the next step of face-exemplar selection. Those that had disparate ratings and that did not fit into a group with other potential face exemplars were discarded from the pool. This process left 30 potential face exemplars arranged into eight groups, ranging from 3 to 8 exemplars per group.

The volunteers in each of the eight groups of potential exemplars were asked to return to the lab to be haptically rated a second time. The two raters were blindfolded and were unaware of the identity of the potential face exemplars. The members of each group were compared with one another in pairs; the raters haptically explored all possible pairs. The raters classified each pair as poor, good, very good, or excellent on the basis of tactual similarity. The three potential face exemplars from each group that were classified as the most similar were chosen to be the face exemplars for the study.

In total, six groups (each with three face exemplars) were chosen. The mean age of the women who volunteered for the face exemplars was 23.6 years $(S D=2.8)$ with a range of 20-30 years. Three of the groups were assigned to Set 1 ; the remaining three groups were assigned to Set 2 . Within each group of three, one exemplar was chosen to be the standard, and the remaining two were designated as the comparisons. The exemplar that was rated as most similar to the other two exemplars was designated as the standard. For example, if $\mathrm{A}$ was rated as excellent in similarity to both B and C, but B was only rated as a very good match to $\mathrm{C}, \mathrm{A}$ would be designated as the standard.

In all conditions, the faces were exposed up to the hairline. The participants were not allowed to explore the head beyond that point or the ears. All the exemplars wore thick, knit headbands to remove potential differentiating cues provided by their hair and to prevent the participants from exploring beyond the exemplars' faces.

Masks. A plaster cast of each exemplar's face, bounded by the hairline, was made. Each face was first coated with petroleum jelly. Gypsona plaster of paris slabs were applied and molded to each face. After 10 min of drying time, the casts were removed from the exemplars' faces. The masks were made by molding Cone 6-8 stoneware clay into the interior surface of the casts, allowing to slowly air dry, and then removing it from the casts. Imperfections on each mask due to artificial bumps and/or crevices in the clay were sponged smooth. The masks were then placed in a kiln and fired at $1700^{\circ} \mathrm{F}$. Again, imperfections due to the clay were removed with 400 -grit sandpaper. Figure 1 shows one group of faces and their corresponding masks as an example.

\section{Procedure}

Haptic exploration-haptic matching of live faces $(\mathbf{H}-\mathbf{H})$. Fifteen participants were randomly assigned to Set 1 face exemplars, and 15 explored the exemplars assigned to Set 2 . The exemplar volunteers were instructed to remain absolutely motionless throughout each trial and to keep their eyes shut. Pretesting practice sessions were carried out so that the exemplar volunteers would become comfortable with the task and could remain motionless. During the task, the participants were required to wear a blindfold, headphones, and to use nasal ointment. White noise was delivered through headphones. Olfactory, auditory, and visual cues were masked in order to ensure that the identification of the standard faces was based solely on haptic information. The participants were asked to familiarize themselves with the standard face through manual exploration; no time constraint was imposed on the duration of exploration. As stated earlier, only the exemplar faces were presented. The participants were not allowed to explore the head beyond the hairline or the ears. The few participants who did attempt to move beyond the headbands (which acted as a boundary between the face and the rest of the head) had their hands gently, but firmly, moved back to the face area. The participants were then sequentially presented with three 


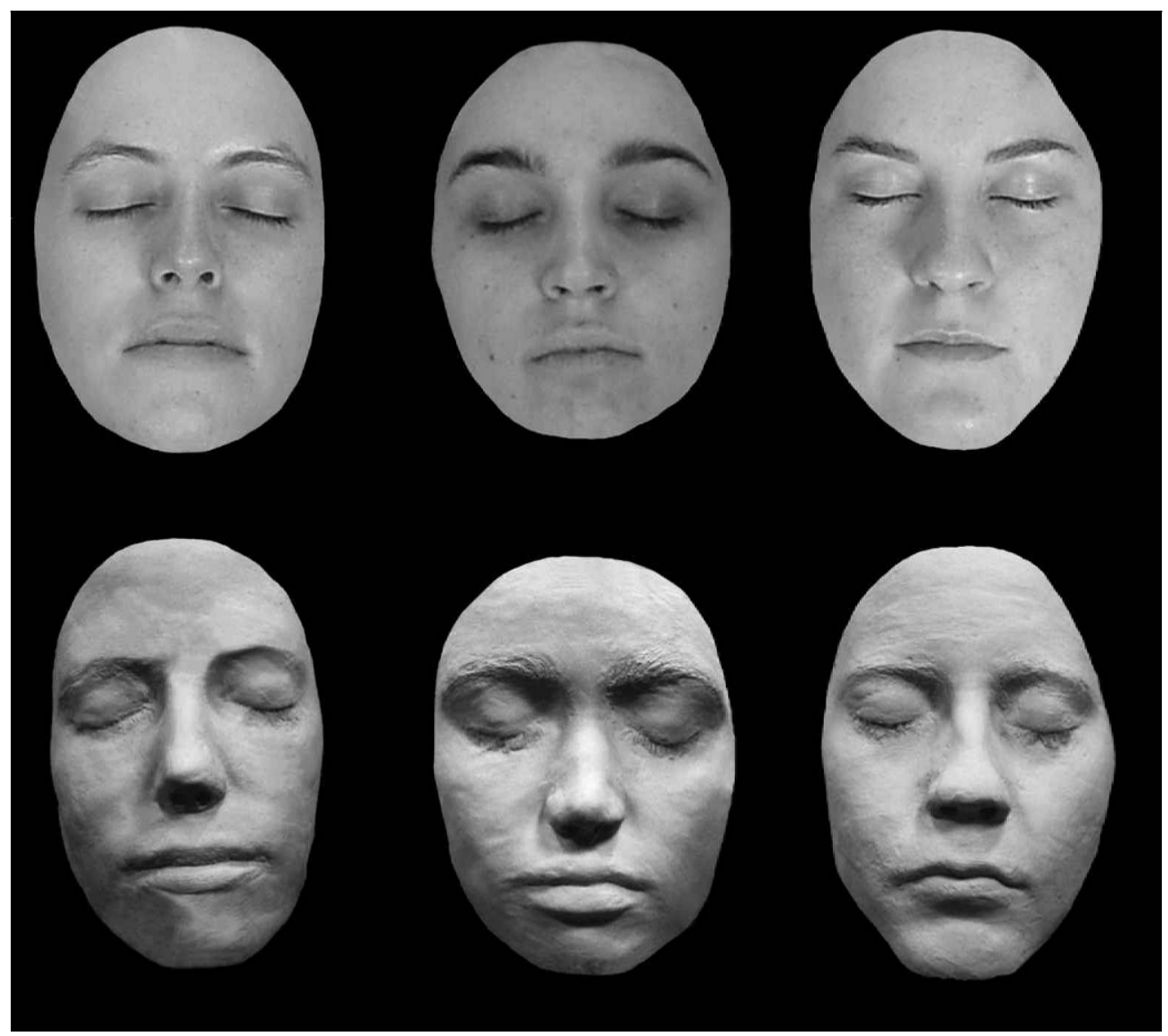

Figure 1. Three of the face exemplars (top row) and their corresponding masks (bottom row). Each face and corresponding mask is from a different exemplar group.

comparison faces, one of which was the standard. Again, only the faces were presented. The participants were not permitted to reexplore a face once they moved on to the subsequent face. The presentation order of the standard was counterbalanced between trials and participants. The participants were asked to identify the standard face and then to rate how comfortable they were with the task. Responses, on a 5-point scale, ranged from 1 (not comfortable) to 5 (very comfortable). Finally, the participants were asked to provide information regarding the characteristics that they used in order to identify the standard face. Responses were not restricted in any way. The participants were allowed as much time as they required in order to ensure that the face information was effectively encoded, inasmuch as the goal of this exploratory study was to maximize accuracy. For each face exemplar (both standard and comparisons), the duration of contact was measured, in seconds, from initial contact to disengagement. Thus we were also able to determine how long it took the participants to match unfamiliar faces at the subordinate level, given the emphasis on accuracy.

The entire procedure was repeated three times in total, with each trial including a different standard and the two appropriate comparisons. Finally, after all three trials, each participant completed the VVIQ.

Visual and haptic input-haptic identification of live faces (VH-H). Thirty participants were randomly assigned to this condition: 15 to the Set 1 exemplars and 15 to the Set 2 exemplars. The procedure was identical to that of the $\mathrm{H}-\mathrm{H}$ condition, with the exception that during the initial exploration phase, the participants were not blindfolded; rather, they were instructed to look at, as well as manually explore, the standard face. As in the $\mathrm{H}-\mathrm{H}$ condition, the participants were blindfolded during the matching phase. As before, the participants completed three trials and then completed the VVIQ.

Haptic input-haptic identification of face masks $\left(\mathrm{H}_{\mathrm{Mask}}{ }^{-}\right.$ $\mathbf{H}_{\text {Mask }}$ ). The procedure used in this condition was identical to that in the $\mathrm{H}-\mathrm{H}$ condition; however, the exemplars consisted of the face masks. Fifteen participants explored the masks that corresponded to the nine exemplars of Set 1 , and 15 participants explored those masks designated as Set 2.

\section{Results}

\section{Accuracy Data}

All but 1 participant explored both the standard and comparison faces bimanually. Each trial was scored as 1 (correct) or 0 (incorrect), and the scores for the three trials were summed. Thus, each participant received a score out of three. These scores were entered into a $2 \times 3$ (set $\times$ condition) analysis of variance (ANOVA). Figure 2 displays the mean percent accuracy across trials for both sets in all three conditions.

The main effect for condition was statistically significant $[F(2,84)=3.91, p<.05]$, but that for set $[F(1,84)=1.10$, $p>.05]$ and for the condition $\times$ set interaction $[F(2,84)=$ 


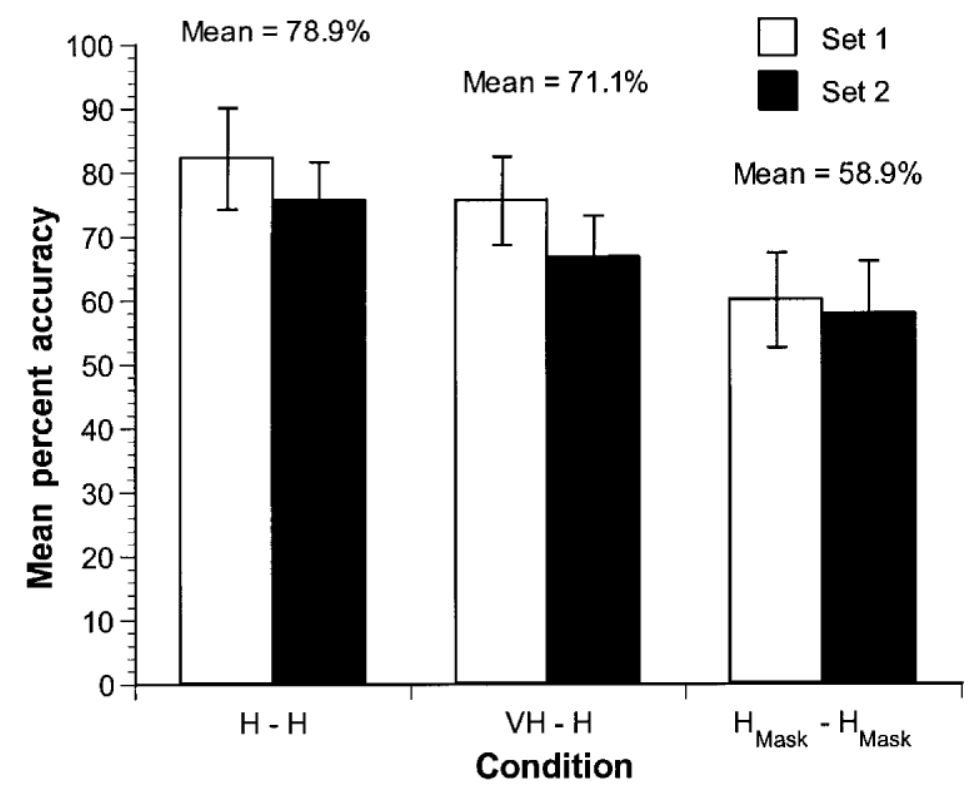

Figure 2. Mean percent accuracy across trials for both sets in all three conditions of Experiment 1.

$0.11, p>.05$ ] were not. Using a significance level of .05 , a post hoc Tukey test revealed that the $\mathrm{H}-\mathrm{H}$ condition was significantly different from the $\mathrm{H}_{\text {Mask }}-\mathrm{H}_{\text {Mask }}$ condition. The $\mathrm{VH}-\mathrm{H}$ condition was included in subsets with both the $\mathrm{H}-\mathrm{H}$ and the $\mathrm{H}_{\text {Mask }}-\mathrm{H}_{\text {Mask }}$ condition, indicating that although this condition was not statistically different from either the $\mathrm{H}-\mathrm{H}$ or $\mathrm{H}_{\text {Mask }}-\mathrm{H}_{\text {Mask }}$ conditions, it tended to lie somewhere between the two.

\section{Diagnostic Facial Characteristics}

As mentioned earlier, each participant was asked to report the facial characteristics that they used to identify the standard face. Each response was assigned a score of 1 and was categorized as either geometric or material. Within the geometric category, the responses were further categorized as either global or local. The local category was then further subcategorized as follows: chin, jaw, cheeks, nose, forehead, brows, lips and upper lip, and eyes. Within the material category, responses were subcategorized as texture, compliance, blemishes, hair, brow texture, and temperature. This categorization system allowed a count of the geometric and material cues in each condition. The relative importance of geometric and material properties was assessed on the basis of these data.

Table 1 summarizes the percentages of cues in the two sets across all three conditions in Experiment 1 (as well as the percentages for Experiment 2). There was no statistically significant difference between the two sets for any of the three conditions.

Although the $\mathrm{H}-\mathrm{H}$ condition relied heavily on geometric cues, material cues were clearly used as well in identifying the standard faces. The participants in the $\mathrm{VH}-\mathrm{H}$ and the $\mathrm{H}_{\text {Mask }}-\mathrm{H}_{\text {Mask }}$ conditions relied heavily on geometric cues, but there was a difference between the conditions in terms of the percent of material cues available and utilized. The percentage of material cues reportedly extracted to identify the standard face in the $\mathrm{VH}-\mathrm{H}$ condition $(24 \%)$ was greater than that in the $\mathrm{H}_{\text {Mask }}-\mathrm{H}_{\text {Mask }}$ condition (4\%) $\left[\chi^{2}(1, N=51)=12.01, p<.001\right]$. Conversely, more geometric cues were used during the $\mathrm{H}_{\text {Mask }}-\mathrm{H}_{\text {Mask }}$ condition than during the $\mathrm{VH}-\mathrm{H}$ condition. Similarly, the percentage of material cues reportedly used in the $\mathrm{H}-\mathrm{H}$ condition $(28.3 \%)$ was greater than in the $\mathrm{H}_{\text {Mask }}-\mathrm{H}_{\text {Mask }}$ condition $\left[\chi^{2}(1, N=51)=32.26, p<.001\right]$. However, there was

Table 1

Summary of Cues Used to Identify the Standard Faces in Experiments 1 and 2

\begin{tabular}{lcc}
\hline Condition & Set & $\begin{array}{c}\text { Geometric \% } \\
\text { of Total }\end{array}$ \\
\hline \multirow{3}{*}{$\mathrm{H}-\mathrm{H}$} & Experiment 1 & \\
& 1 & 73.4 \\
\multirow{2}{*}{$\mathrm{VH}-\mathrm{H}$} & 2 & 70.0 \\
& Mean & 71.7 \\
\multirow{2}{*}{$\mathrm{H}_{\text {Mask }}-\mathrm{H}_{\text {Mask }}$} & 1 & 84.9 \\
& 2 & 67.0 \\
& Mean & 76.0 \\
& 1 & 95.7 \\
$\mathrm{~V}-\mathrm{H}$ & 2 & 96.1 \\
& Mean & 95.9 \\
& Experiment 2 & \\
$\mathrm{H}-\mathrm{V}$ & 1 & 95.3 \\
& 2 & 84.9 \\
& Mean & 90.1 \\
& 1 & 80.0 \\
& 2 & 79.5 \\
& Mean & 79.8 \\
\hline
\end{tabular}


no statistically significant difference between the percentage of material cues used in the $\mathrm{H}-\mathrm{H}$ and $\mathrm{VH}-\mathrm{H}$ conditions $\left[\chi^{2}(1, N=51)=0.85, p>.05\right]$.

\section{Response Time Data}

Two response time measures were considered: (1) standard response time - that is, duration of contact with the standard face only; and (2) total response time-that is, standard response time plus the response times for each comparison face exemplar. The significance of these measures will be discussed in the General Discussion section. These data violated the assumptions for ANOVA in that the data were positively skewed. Accordingly, the data were subjected to a logarithmic transformation, after which the data met the assumptions. Nevertheless, the pattern of the transformed data was identical to the pattern of the raw data; therefore, Figure 3 shows the both the standard and the total response times (untransformed).
Standard RT. The transformed data were entered into a $3 \times 2 \times 3$ ANOVA (trial $\times$ set $\times$ condition). Statistically significant main effects were found for trial $[F(2,168)=$ $26.55, p<.0001]$ and for condition $[F(2,84)=13.65, p<$ $.0001]$. Trial 1 took longer than both Trials 2 and 3 . As expected, the standard response time for the participants in the $\mathrm{VH}-\mathrm{H}$ condition was faster than for the participantsin the $\mathrm{H}-\mathrm{H}$ and $\mathrm{H}_{\text {Mask }}-\mathrm{H}_{\text {Mask }}$ conditions. There was no main effect of set, nor were any of the interactions statistically significant.

Total RT. The transformed data were entered into a $3 \times$ $2 \times 2$ ANOVA (trial $\times$ set $\times$ condition). Statistically significant main effects were found for trial $[F(2,168)=$ $78.82, p<.0001]$ and for condition $[F(2,84)=3.81, p<$ .05]. Trial 2 was faster than either Trial 1 or Trial 3, which did not statistically differ from one another. The participants in the $\mathrm{VH}-\mathrm{H}$ condition were faster overall than those in the $\mathrm{H}-\mathrm{H}$ or $\mathrm{H}_{\text {Mask }}-\mathrm{H}_{\text {Mask }}$ conditions.

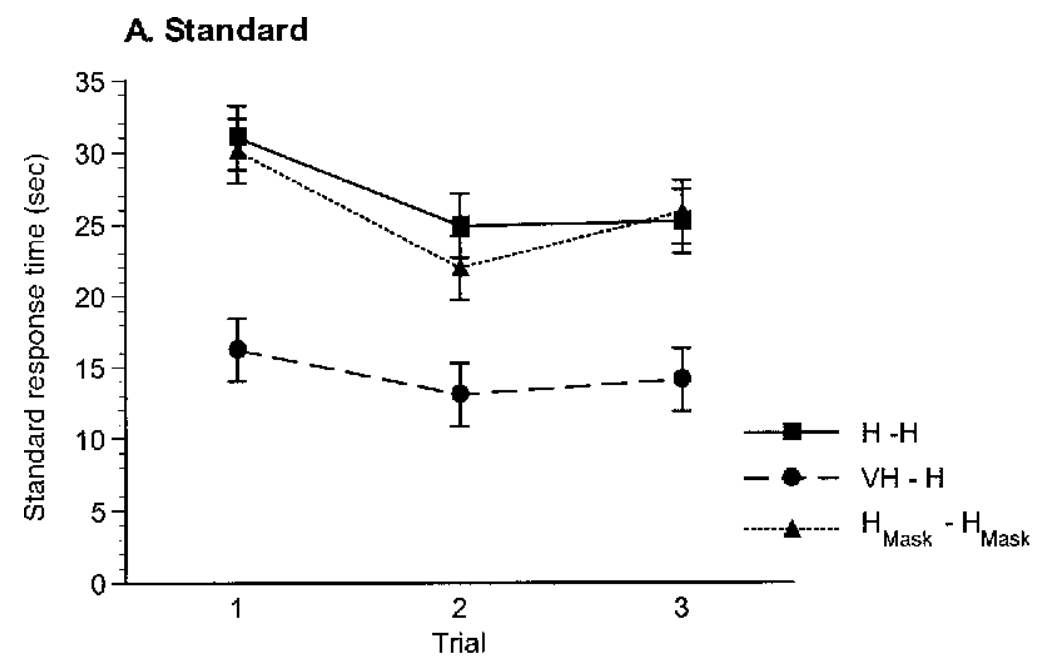

B. Total

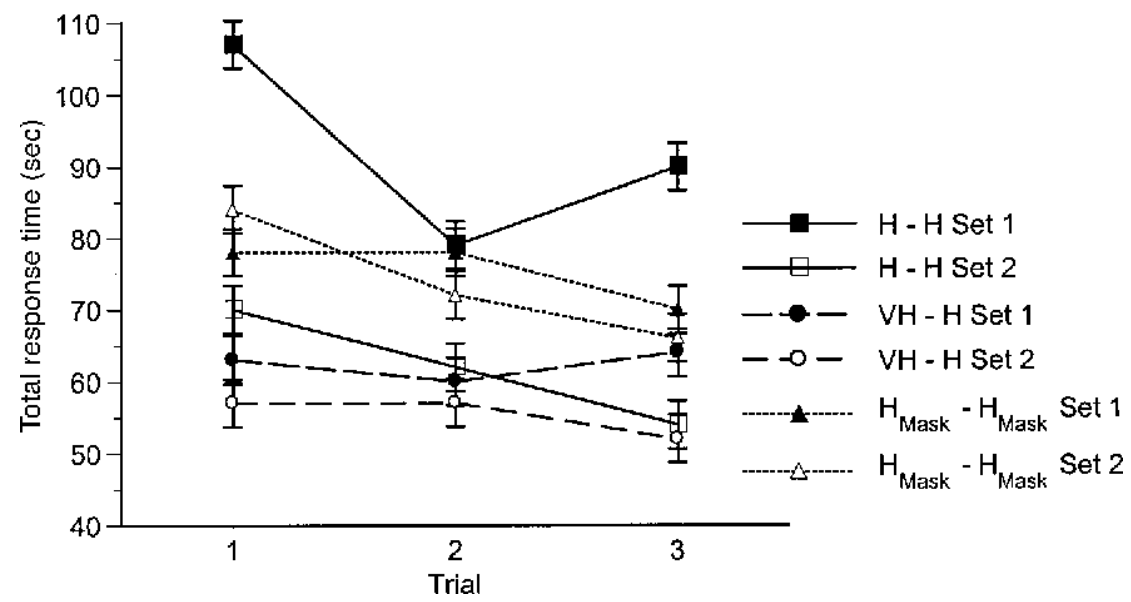

Figure 3. Standard and total response times (in seconds) for both sets (total response time only) and all three conditions of Experiment 1 . The conditions in panels $A$ and $B$ are represented by the same symbols and line styles; however, since both sets are shown in panel B, Set 1 is represented by filled symbols, whereas Set 2 is represented by open symbols. 
Additionally, there were several significant interactions: (1) trial $\times \operatorname{set}[F(2,168)=70.61, p<.0001],(2)$ trial $\times$ condition $[F(4,168)=52.63, p<.0001]$, (3) trial $\times$ set $\times$ condition $[F(4,168)=42.05, p<.0001]$, and (4) set $\times$ condition $[F(2,84)=8.51, p<.0001]$. To briefly summarize these interactions, the participants in Set 1 performed the task faster on Trial 2 but only in the $\mathrm{H}_{\text {Mask }}{ }^{-}$ $\mathrm{H}_{\text {Mask }}$ condition. The speeds of Trials 1, 2, and 3 during Set 2 were statistically equal to one another for all three conditions, as were all Set 1 trials in the $\mathrm{VH}-\mathrm{H}$ condition.

\section{VVIQ Data}

Table 2 displays both the mean VVIQ scores and their correlations with both accuracy and total response time, for each condition in Experiment 1 (and for Experiment 2). These VVIQ scores are indicative of a fair ability to employ visual imagery. Recall that the score reflecting the best ability to visually image is 16 , whereas higher scores, to a maximum of 80 , reflect poor ability to image. We anticipated that if the participants had adopted a visualmediation heuristic, the VVIQ scores should be negatively correlated with accuracy and positively correlated with response time. None of the correlation coefficients was significant. In fact, most of the correlation values between VVIQ and accuracy were opposite the expected direction.

\section{Comfort Ratings}

A mean comfort rating for each participant was calculated from the ratings given after each of the three trials. With the scale used, 1 represents not comfortable and 5 represents very comfortable. The mean comfort ratings for the $\mathrm{H}-\mathrm{H}$ condition for Sets 1 and 2 are $3.3(S D=.92)$ and $3.9(S D=.86)$, respectively. The mean comfort ratings for the $\mathrm{VH}-\mathrm{H}$ conditions for Sets 1 and 2 are $4.2(S D=$ $.59)$ and $3.8(S D=.83)$, respectively, and for the $\mathrm{H}_{\text {Mask }}{ }^{-}$ $\mathrm{H}_{\text {Mask }}$ conditions for Sets 1 and 2 are $4.1(S D=.84)$ and $3.9(S D=.77)$, respectively.

These means were compared in a $2 \times 3$ ANOVA (set $X$ condition). Neither the main effect for set $[F(1,84)=0.19$, $p>.05]$ nor the main effect for condition $[F(2,84)=2.05$, $p>.05]$ was statistically significant. However, the set $\times$ condition interaction was significant $[F(2,84)=3.22$, $p<.05]$, although there were no statistically significant differences in comfort ratings between the two sets for the $\mathrm{VH}-\mathrm{H}$ and $\mathrm{H}_{\text {Mask }}-\mathrm{H}_{\text {Mask }}$ conditions, in the $\mathrm{H}-\mathrm{H}$ condition, the participants in Set 1 scored significantly lower, indicating that the participants' discomfort with the task did not affect their performance detrimentally, since the participants in Set 1 achieved $82.2 \%$ matching accuracy.

Furthermore, comfort ratings were not correlated with the amount of time spent exploring the standard faces $(r=$ $.068, p=.53$ ). Thus, discomfort with the task did not seem to effect premature disengagement for the standard faces.

\section{Discussion}

The primary questions investigated in Experiment 1 were: (1) Is the haptic system capable of identifying an unfamiliar human face at the subordinate level, using a match-to-sample paradigm; (2) how do participants encode faces on the basis of haptically derived inputs; (3) how is matching performance affected when participants are biased more toward processing geometric information; and (4) is visual mediation used? The results of the present study show that the haptic system is quite good at processing and identifying unfamiliar human faces at the subordinate level. Blindfolded participants identified the standard face from among three comparison faces with an accuracy of up to $82.2 \%$. This value is well above the chance level of $33 \%$.

We predicted that accuracy would be higher in the VH$\mathrm{H}$ condition than in the $\mathrm{H}-\mathrm{H}$ condition, since both visual input and haptic input were allowed during the exploration phase. Vision is both practiced and highly accomplished in face-processing tasks. In fact, in a preliminary study, we had participants perform an intramodal task with vision (visual input and visual identification; $\mathrm{V}-\mathrm{V}$ ) using the face masks. Performance was at ceiling - that is, at $100 \%$ accuracy. Furthermore, the combination of visual and haptic

Table 2

VVIQ Scores and Correlation Between VVIQ and Accuracy for Experiments 1 and 2

\begin{tabular}{|c|c|c|c|c|c|}
\hline \multirow[b]{2}{*}{ Condition } & \multirow[b]{2}{*}{ Set } & \multicolumn{2}{|c|}{ VVIQ Score } & \multirow{2}{*}{$\begin{array}{c}\text { Correlation With } \\
\text { Accuracy* }\end{array}$} & \multirow{2}{*}{$\begin{array}{c}\text { Correlation With Total } \\
\text { Response Time* }\end{array}$} \\
\hline & & $M$ & $S D$ & & \\
\hline \multicolumn{6}{|c|}{ Experiment 1} \\
\hline $\mathrm{H}-\mathrm{H}$ & $\begin{array}{l}1 \\
2\end{array}$ & $\begin{array}{l}32.9 \\
33.2\end{array}$ & $\begin{array}{l}8.5 \\
7.7\end{array}$ & $\begin{array}{r}.10 \\
-.14\end{array}$ & $\begin{array}{r}.05 \\
-.14\end{array}$ \\
\hline VH-H & $\begin{array}{l}1 \\
2\end{array}$ & $\begin{array}{l}32.8 \\
35.5\end{array}$ & $\begin{array}{l}9.5 \\
5.9\end{array}$ & $\begin{array}{l}.27 \\
.16\end{array}$ & $\begin{array}{r}.25 \\
-.24\end{array}$ \\
\hline $\mathrm{H}_{\text {Mask }}-\mathrm{H}_{\text {Mask }}$ & $\begin{array}{l}1 \\
2\end{array}$ & $\begin{array}{l}33.8 \\
39.9\end{array}$ & $\begin{array}{l}7.4 \\
9.6\end{array}$ & $\begin{array}{r}.24 \\
-.45\end{array}$ & $\begin{array}{r}.38 \\
-.17\end{array}$ \\
\hline \multicolumn{6}{|c|}{ Experiment 2} \\
\hline $\mathrm{V}-\mathrm{H}$ & $\begin{array}{l}1 \\
2\end{array}$ & $\begin{array}{l}34.5 \\
36.7\end{array}$ & $\begin{array}{l}6.2 \\
6.8\end{array}$ & $\begin{array}{l}-.44 \\
-.04\end{array}$ & $\begin{array}{l}- \\
-\end{array}$ \\
\hline $\mathrm{H}-\mathrm{V}$ & $\begin{array}{l}1 \\
2\end{array}$ & $\begin{array}{l}36.3 \\
34.0\end{array}$ & $\begin{array}{l}7.4 \\
7.2\end{array}$ & $\begin{array}{r}-.33 \\
.03\end{array}$ & $\begin{array}{l}- \\
-\end{array}$ \\
\hline
\end{tabular}

$*$ no $p$ value $<.05$. 
input modalities was highly complementary since it makes use of the superior processing skills of vision with respect to geometric properties and the superior processing skills of the haptic system with respect to material information. Indeed, Newman, Sawyer, Hall, and Hill (1990) found that during a haptic-matching task involving braille characters, vision and haptic exploration resulted in more accurate haptic matching than did haptic-only exploration (cf. the $\mathrm{H}-\mathrm{H}$ condition). However, contrary to prediction and past results, there was no difference in accuracy between the two conditions $(\mathrm{H}-\mathrm{H}$ and $\mathrm{VH}-\mathrm{H})$. If anything, performance tended to be in the opposite direction. Although there was no statistically reliable difference between the two conditions, the $\mathrm{VH}-\mathrm{H}$ condition tended ( $71.1 \%$ accuracy) to be poorer than the $\mathrm{H}-\mathrm{H}$ condition ( $78.8 \%$ accuracy). These results suggest that the visual input may have drawn attention away from the haptic input (see Heller, Calcaterra, Green, \& Brown, 1999).

In the $\mathrm{H}_{\text {Mask }}-\mathrm{H}_{\text {Mask }}$ condition, there was no variation in material properties. Accordingly, we predicted that matching accuracy would decline relative to the $\mathrm{H}-\mathrm{H}$ condition, as was indeed the case.

Klatzky et al. (1985) demonstrated that their participants were able to identify a large number of common objects accurately and quickly. These objects were classified at the basic level. In contrast, the match-to-sample task in the present experiment required classification at the subordinate level, since all the exemplars were from the same basiclevel class - that is, faces. As such, the task was somewhat more difficult than that performed by Klatzky et al.'s (1985) participants. Moreover, their objects were highly familiar. The Kaitz et al. (1992; Kaitz et al., 1993; Kaitz et al., 1994) studies also used exemplars that were highly familiar to the participants. In contrast, the participants in the present study did not know the "objects" at all; yet, they were able to haptically identify the standard faces at a relatively high level of accuracy.

Our participants used both geometric and material cues in the match-to-sample task, although they placed greater emphasis on the geometric cues. Nonetheless, up to $30 \%$ of all cues reported were material in nature. It can be inferred, therefore, that haptic face encoding at the subordinate level involves both geometric and material properties.

The results of the present experiment clearly highlight the importance of material cues in haptic face identification. Without question, geometric, or structural, cues are important in any identification/recognition task. However, when all the geometric cues remained available, whereas while the material cues were removed (the $\mathrm{H}_{\text {Mask }}-$ $\mathrm{H}_{\text {Mask }}$ condition), identification accuracy dropped by $20 \%$ relative to the $\mathrm{H}-\mathrm{H}$ condition, in which the material cues were available. Nevertheless, the $58.8 \%$ accuracy obtained in the $\mathrm{H}_{\text {Mask }}-\mathrm{H}_{\text {Mask }}$ condition remains above chance level.

There was no evidence to support the image-mediation model, since there was no correlation between the participants' ability to use visual imagery and matching accuracy or total response time. That is, the participants did not appear to include a visual-translation stage when performing the face-matching task haptically.

\section{EXPERIMENT 2}

Experiment 2 examined whether intersensory transfer would occur, and if so, whether it would be constrained by the input modality used to explore the standard face. Two conditions were included: vision as the input modality with haptic matching $(\mathrm{V}-\mathrm{H})$ and haptics as the input modality with visual matching $(\mathrm{H}-\mathrm{V})$. Given that both infants (e.g., Meltzoff \& Borton, 1979) and children (e.g., Bushnell \& Baxt, 1999) can successfully perform intermodal matching, we predicted that adult participants would be able to accurately identify the standard faces with above-chance accuracy. However, on the basis of Jones' (1981) findings, we expected that the $\mathrm{H}-\mathrm{V}$ condition would result in poorer matching accuracy than the $\mathrm{V}-\mathrm{H}$ condition. He argued that when touch is the input modality, cross-modal tasks tend to result in poorer performance than when vision is the input modality, owing to insufficient haptic processing.

Once again, the participants were asked to report the cues they had used to identify the standard faces. We planned to use these reports to guide our speculations concerning how faces were encoded during the intermodal-matching task.

Since vision was involved in both conditions, it was not unreasonable to expect that the participants might adopt a visual-mediation strategy to identify the standard faces. To explore this possibility, the participants were administered the VVIQ.

\section{Method}

\section{Participants}

Sixty undergraduate students (14 men and 46 women, mean age, 20.4 years, $S D=3.2$ ) participated in this study in partial fulfillment of an introductory psychology course credit. Testing procedures met with the standards of the Ethics Review Committee in the Department of Psychology at Queen's University.

\section{Materials}

The six groups of exemplar faces used in Experiment 1 also served as the face exemplars in Experiment 2. A Quasar S-VHS video camera was used to record the participants' responses. The VVIQ was administered to each participant. A portable stereo system was used to present white noise to the participants through headphones.

\section{Procedure}

Visual input-haptic identification of live faces $(\mathbf{V}-\mathbf{H})$. Thirty participants were randomly assigned to this condition; 15 were exposed to the exemplars assigned to Set 1 , and 15 explored the exemplars assigned to Set 2 . The procedure was identical to that of Experiment 1 , with the exception that during the initial exploration phase, the participants were not blindfolded; rather, they were instructed to look at the standard face. The hair and ears of each exemplar were covered with a wide headband so that only the face was in view. Haptic exploration was not permitted. As in Experiment 1, the matching phase proceeded with the participants' being blindfolded. Once again, they completed three trials, after each of which they gave a comfort rating and reported the cues that they used to identify the standard. After all three trials, the participants completed the VVIQ.

Haptic input-visual matching of live faces $(\mathrm{H}-\mathrm{V})$. Thirty participants were randomly assigned to this condition; 15 were exposed to Set 1 and 15 to Set 2 exemplars. The procedure was exactly the reverse of that used in the $\mathrm{V}-\mathrm{H}$ condition. During the initial exploration phase, the participants were required to explore the standard face using touch alone. As in Experiment 1, the standard response 
time was measured from initial contact with the standard face to disengagement from the face. Matching was executed visually, after which each participant completed the VVIQ.

\section{Results}

\section{Accuracy Data}

As in Experiment 1, accuracy scores were summed across trials to produce a score up to a maximum of 3 for each participant. Figure 4 presents mean identification accuracy for the two intermodal conditions. A $2 \times 2$ (set $\times$ condition) ANOVA revealed that there was no main effect of set $[F(1,56)=0.03, p>.05]$ but that there was a main effect of condition $[F(1,56)=4.46, p<.05]$. The set $\times$ conditioninteraction was also significant $[F(1,56)=$ $7.63, p<.01]$. For Set 2 trials, accuracy did not statistically differ between the two conditions; however, for Set 1 trials, accuracy was significantly better in the $\mathrm{V}-\mathrm{H}$ condition than in the $\mathrm{H}-\mathrm{V}$ condition. In fact, for Set 1 , the mean percent accuracy obtained by the $\mathrm{H}-\mathrm{V}$ participants $(44.4 \%)$ was not statistically above chance $[t(28)=1.32, p=.21]$. The percent accuracy obtained by the $\mathrm{V}-\mathrm{H}$ participants in both sets and by the $\mathrm{H}-\mathrm{V}$ participants in Set 2 were all well above chance $[t(28)=10.58, p<.0001 ; t(28)=3.21$, $p=.006$; and $t(28)=4.52, p<.0001$, respectively $]$.

\section{Diagnostic Facial Characteristics Data}

Table 1 also shows the percentage of peometric cues that the participants reported using to identify the standard faces. Although both conditions relied heavily on geometric cues, the two conditions differed in terms of the percentage of geometric and material cues used. The number of material cues reportedly used to identify the standard face in the $\mathrm{V}-\mathrm{H}$ condition was statistically lower than that in the $\mathrm{H}-\mathrm{V}$ condition $\left[\chi^{2}(1)=9.6, p<.01\right]$. Conversely, geometric cues were used more in the $\mathrm{V}-\mathrm{H}$ condition than in the $\mathrm{H}-\mathrm{V}$ condition. These two patterns held across sets.

\section{Response Time Data}

The $\mathrm{H}-\mathrm{V}$ condition consisted of the visual exploration of all three comparisons. However, as the timing of this exploration could not be precisely measured, the total response time was not assessed. In being positively skewed, the standard response time data violated both the assumptions of normality and homogeneity of variance for the ANOVA; therefore, the data were subjected to a logarithmic transformation.

The transformed data were entered into a $3 \times 2 \times 2$ ANOVA (trial $\times$ set $\times$ condition). Mean response times of the untransformed data are shown in Figure 5, because the patterns were quite similar to those of the transformed data. There was a main effect for trial $[F(2,112)=3.44, p<$ .05 ] so that Trials 1 and 2 took longer than Trial 3. With respect to the between-subjects factors, there was a main effect of condition $[F(1,56)=18.68, p<.0001]$ but there was no main effect of set $[F(1,56)=0.14, p>.05]$. As expected, time spent exploring the standard face in the $\mathrm{V}-\mathrm{H}$ condition was not as long as in the $\mathrm{H}-\mathrm{V}$ condition. None of the interactions with trial was statistically significant.

\section{VVIQ Data}

Table 2 displays the mean VVIQ scores for Experiment 2, as well as the correlations between VVIQ and accuracy scores for both conditions in Experiment 2. None of the correlations was significant, although two were in the expected direction. As explained above, total response times were not measured in Experiment 2 and thus were unavailable for correlating with VVIQ scores.

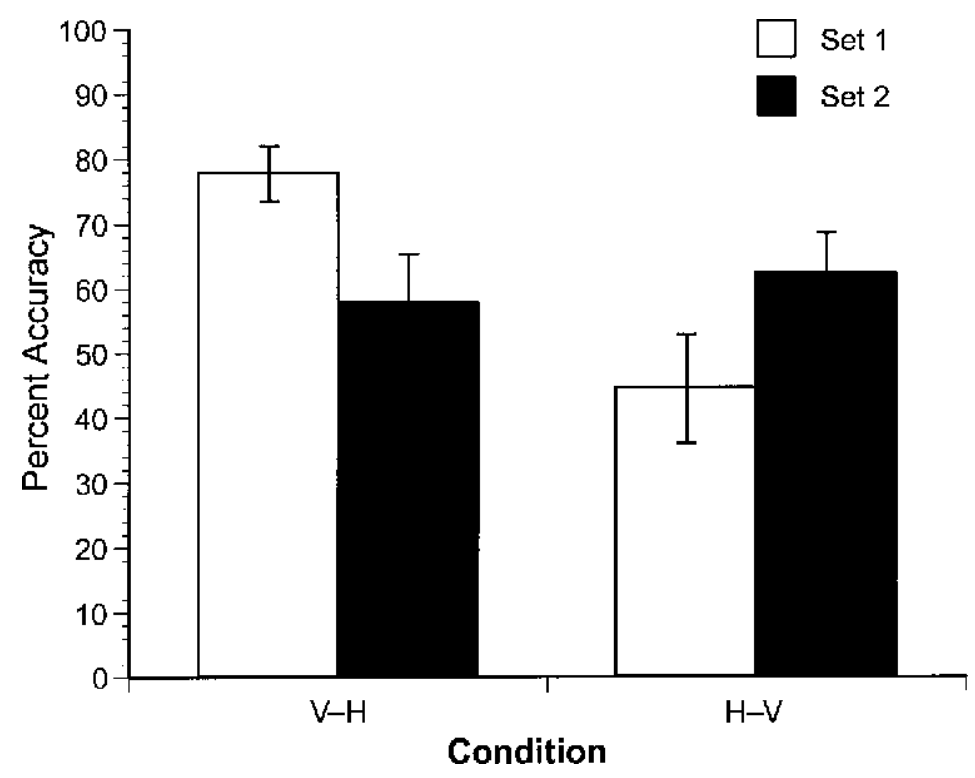

Figure 4. Mean percent accuracy across trials for both sets and conditions of Experiment 2. 


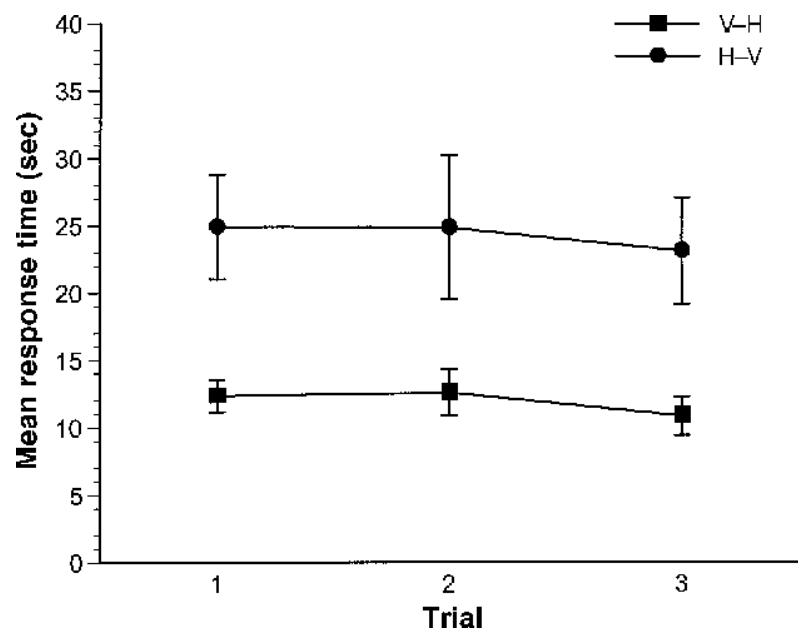

Figure 5. Standard response times (in seconds) for both sets and conditions of Experiment 2.

\section{Comfort Ratings}

The overall mean comfort rating was $3.4(S D=0.93)$ for the $\mathrm{V}-\mathrm{H}$ condition and $3.7(S D=0.97)$ for the $\mathrm{H}-\mathrm{V}$ condition. The scores were out of a possible 5 points, with 5 representing no discomfort with the task. Comfort-rating means were entered into a $2 \times 2$ ANOVA (set $\times$ condition). Neither the main effect for set $[F(1,56)=1.64, p>.05]$, nor the main effect for condition $[F(1,56)=2.42, p>.05]$, was statistically significant. Likewise, the interaction term was not significant $[F(1,56)=0.76, p>.05]$.

Subjective ratings of comfort with the task did not correlate with accuracy in identifying the standard faces $(r=$ $-.13, p=.32$ ), nor was there a significant correlation between comfort ratings and standard response time $(r=.19$, $p=.14)$. These findings indicate that the participants' discomfort with the task did not detrimentally affect accuracy of performance.

\section{Discussion}

In the two conditions of this experiment, we addressed the issue of intersensory transfer. In three of the four cases, there was clear evidence of intersensory transfer: Both Sets 1 and 2 in the $\mathrm{V}-\mathrm{H}$ condition and Set 2 in the $\mathrm{H}-\mathrm{V}$ condition demonstrated intersensory transfer. On the basis of previous research (e.g., Jones, 1981; Newman et al., 1990), we predicted that the $\mathrm{V}-\mathrm{H}$ condition would produce higher accuracy than would the $\mathrm{H}-\mathrm{V}$ condition. This prediction was not fully supported since there was a set $\times$ condition interaction. The results of Set 1 followed the predicted pattern: Identification of the standard face was more accurate in the $\mathrm{V}-\mathrm{H}$ condition than in the $\mathrm{H}-\mathrm{V}$ condition. It cannot be said, however, that the $\mathrm{H}-\mathrm{V}$ condition was poorer than the $\mathrm{V}-\mathrm{H}$ condition, owing to insufficient haptic processing of the standard (Jones, 1981) for two reasons that will be specifically discussed in the General Discussion section. Nor can these results be attributed to a memory load problem resulting from a delay between the input and identification phases. As stated earlier, a preliminary $\mathrm{V}-\mathrm{V}$ condition that contained a similar inputto-identification delay resulted in $100 \%$ identification accuracy.

On the whole, the three groups of exemplar faces used in Set 2 were rated as more similar to one another than were the three groups used in Set 1, suggesting that the task in Set 2 was more difficult than that in Set 1. The difficulty in identifying the standard face was evident in the $\mathrm{V}-\mathrm{H}$ condition. Although the participants involved in Set 1 were able to identify the standard with $77.8 \%$ accuracy, those in Set 2 achieved only $57.8 \%$ accuracy. However, this explanation does not hold for the $\mathrm{H}-\mathrm{V}$ condition, in which accuracy increased by $18 \%$ from Set 1 to Set 2 . The $\mathrm{H}-\mathrm{V}$ condition produced $44.4 \%$ accuracy for Set 1 (i.e., chance level), whereas performance in the same condition was $62.2 \%$ accurate for Set 2 . Within Set 2 trials, performance accuracy did not differ between the two conditions. These findings are difficult to explain. However, an inconsistency in the exemplar-selection procedure is possible in research that involves choosing exemplars on the basis of similarity, inasmuch as similarity was difficult to operationalize.

\section{GENERAL DISCUSSION}

Until now, research on face processing has focused on the visual system. The literature has addressed several critical issues, as briefly described here. One of the issues most frequently considered has been whether faces are processed featurally or holistically - that is, as entire gestalts (e.g., Bartlett \& Searcy, 1993; Bruce, Doyle, Dench, \& Burton, 1991; Sergent, 1984; Tanaka \& Farah, 1993). To address this issue, several operational definitions of featural and configural have been proposed (e.g., Diamond \& Carey, 1986; Rhodes, 1988). Although these definitions differ from one another, the common theme has been that faces include two types of information: specific appearance and location of discrete facial features (i.e., nose and eyes) and spatial relations among discrete features.

A second important topic in visual face processing has been the neuroanatomicallocation that underlies visual face processing. Much of the research (e.g., Clarke, Lindemann, Maeder, Borruat, \& Assal, 1997; McCarthy, Puce, Gore, \& Allison, 1997) points to the fusiform gyri (particularly in the right hemisphere) as the significant neural substrate.

A third critical issue in visual face processing concerns whether face processing is an innate or learned task. Cohen-Levine, Banich, and Koch-Weser (1988) argued that, relative to other visuospatial stimuli, humans have developed an expertise through constant exposure to faces and practice in recognizing and differentiating them. Other researchers (e.g., Farah et al., 1998; Johnson, Dziurawiex, Ellis, \& Morton, 1991) have maintained that visual face recognition is a special, innate ability that is separate from visual processing of other nonface objects.

The present study has addressed issues that specifically pertain to haptic face processing and to intersensory trans- 
fer between vision and haptics. This work therefore extends the study of face processing beyond the visual domain and examines face processing from several new perspectives. The relevance of the present study on haptic face processing to all three issues above will be discussed below.

\section{Accuracy of Haptic Face Processing}

The research reported in this article represents an initial investigation of haptic face processing. Live faces were able to be identified with reasonably high accuracy $(78.9 \%)$ solely through haptic exploration (the $\mathrm{H}-\mathrm{H}$ condition). When rigid masks of the same faces were presented as the exemplars, matching accuracy remained above chance but proved considerably poorer $(58.9 \%)$ than that obtained with the live-face exemplars (the $\mathrm{H}_{\text {Mask }}-\mathrm{H}_{\text {Mask }}$ condition). Somewhat more surprisingly, when the participants were also permitted to use vision during exploration, matching accuracy did not improve $(71.1 \%)$ relative to the $\mathrm{H}-\mathrm{H}$ condition, indicating that additional redundant visual inputs were not useful when haptics was used alone in the comparison phase (the $\mathrm{VH}-\mathrm{H}$ condition). Is it possible that the participants largely disregarded the visual geometric information because they knew that they would be required to match haptically? Such an interpretation is not supported by the data. The response times for the $\mathrm{VH}-\mathrm{H}$ condition dropped to one-half of those for the two hapticsonly conditions $\left(\mathrm{H}-\mathrm{H}\right.$ and $\mathrm{H}_{\text {Mask }}-\mathrm{H}_{\text {Mask }}$ ). This decline indicates that the participants did not disregard visual input. Furthermore, the $\mathrm{VH}-\mathrm{H}$ participants reported using a higher percentage of geometric cues than did the $\mathrm{H}-\mathrm{H}$ participants, particularly in Set 1. It is more likely that the visual input detracted from the haptic input (Heller et al., 1999).

Previous research has demonstrated that even infants are capable of intermodal transfer between the visual and haptic modalities (Meltzoff \& Borton, 1979); therefore, it was reasonable to predict that adults could perform the intermodal face-identification task. For the most part, intermodal transfer did occur. Overall, the $\mathrm{V}-\mathrm{H}$ participants were able to match the standard and comparison faces with $67.7 \%$ accuracy, with accuracy in both sets above chance ( $77.8 \%$ and $57.7 \%$, respectively). On average, the $\mathrm{H}-\mathrm{V}$ participants also performed matching above chance levels $(53.3 \%)$. However, when broken down by set, the Set 1 participants did not match the standard faces above chance $(44.4 \%)$, whereas the Set 2 participants did match above chance $(62.2 \%)$.

The poor matching performance of the $\mathrm{H}-\mathrm{V}$ participants in Set 1 cannot be attributed to the haptic input's being inadequately processed, as Jones (1981) would have argued. The results of Experiment 1, in which participants' matching accuracy was as high as $82.2 \%$, clearly demonstrate that haptic input is more than sufficient for face identification. Nor is it the case that intermodal transfer was impossible, given that the $\mathrm{H}-\mathrm{V}$ participants in Set 2 performed well above chance. As for the expected difference in intermodal performance with direction-initial visual input was expected to produce higher matching ac- curacy than initial haptic input - this was only confirmed with the Set 1 participants; the matching performances of both $\mathrm{V}-\mathrm{H}$ and $\mathrm{H}-\mathrm{V}$ participants in Set 2 were equally above chance. The reason for the anomaly is not immediately apparent. It is possible that the qualitative similarity scale used to select stimulus exemplars may have produced a less precise estimate of similarity and, therefore, the puzzling result. In all other aspects, the two sets produced comparable patterns. We could have chosen to collapse both sets into one set, and, therefore, each participant would have completed six trials rather than three. Had we done so, the anomalous result would not even have been apparent. Our aim, however, was to attain a level of generalizability by including two different face sets explored by two groups of participants.

Haptic face identification was an unusual task for our participants, one that required them to intrude on other people's personal space. Since participants' comfort, or rather discomfort, with the task may have detrimentally influenced matching accuracy, we also assessed their degree of comfort. We were concerned that strong discomfort with the task might decrease identification accuracy. Should this have occurred, the participants might then have minimized the extent of haptic exploration and, consequently, their level of accuracy. On the contrary, even when the participants did express discomfort with the task, their accuracy remained high. The $\mathrm{H}-\mathrm{H}$ participants (Experiment 1) achieved an overall accuracy level of $78.9 \%$, which was the highest accuracy documented in the present study. Yet, these same participants also tended to report that they were more uncomfortable with the task. Furthermore, there was no correlation between comfort and response time. Thus, even if the participants were uncomfortable with the task, they did not prematurely disengage from exploration.

\section{The Nature of Face Representation: Material/Geometric Distinction}

In general, the vision literature has focused on perceptual face representation in terms of geometric properties only. The issue of featural versus configural processing highlights this emphasis. The present study extended the examination of face representation by introducing a geometric/material distinction, one that has proved relevant to the nature of haptic processing.

Despite the absence of a visual-translation stage, geometric properties formed an important component of the participants' representations of faces, regardless of condition. The participants in Experiment 1 reported having used approximately $70 \%$ geometric properties and $30 \%$ material properties. These percentages indicate that material properties were also very important. When the participants were further biased toward encoding faces on the basis of geometric properties - by reducing (the $\mathrm{VH}-\mathrm{H}$ condition) and eliminating (the $\mathrm{H}_{\text {Mask }}-\mathrm{H}_{\text {Mask }}$ condition) material properties - matching accuracy declined, sometimes dramatically. Experiment 2 showed once again that geometric properties were strongly represented, particularly when the initial standard exploration was carried out visually. 
In all cases, the experimental manipulations produced the expected patterns in the data, even if the results were not always significant.

Collectively, the results therefore suggest that although geometric properties are clearly important in encoding faces haptically, material properties play a critical subsidiary role. The present findings are also therefore concordant with those in the literature emphasizing the importance of material properties to representations of nonface objects from haptically derived inputs (e.g., Klatzky et al., 1987; Lederman et al., 1996).

\section{Processing Issues}

Is visual translation present? An important issue investigated in the present study was whether participants with lower VVIQ scores (i.e., higher ability for visual imagery) would demonstrate higher identification accuracy, therefore providing evidence that a visual-mediation heuristic was adopted. Such a result would have been consistent with past research, which has demonstrated that participants adopted an image-mediation model when recognizing raised 2-D pictures of common objects (Lederman et al., 1990). Like identification of 2-D line drawings, the match-to-sample task in the present investigation was difficult for participants, and, therefore, they might have taken advantage of any strategy to successfully complete the task. If this were the case, VVIQ and matching accuracy scores should have been negatively correlated. In addition, we might have expected VVIQ scores to be positively correlated with total response time- the lower the VVIQ score (signifying higher imaging ability), the lower the response time. However, the present data did not support the use of an image-mediation model of haptic face processing. Nor do these null findings appear to be due simply to a lack of power, inasmuch as the Lederman et al. (1990) study included only 20 participants, whereas 30 participants were used in each correlational calculation in the present research.

Speed of processing. The response time data confirmed the expected differences between visual and haptic search. Generally speaking, when the exploration phase was solely haptic, the participants spent twice as much time on the standard face as when the exploration phase included vision. The mean time spent exploring the standard faces was approximately 30 and $15 \mathrm{sec}$, respectively. The difference in response times that we found provides evidence that the visual, geometric information provided during the $\mathrm{VH}-\mathrm{H}$ condition was not disregarded.

In summary, the present study addressed several important issues that pertain to haptic face processing and to intersensory transfer between vision and haptics. It therefore extends the study of face processing beyond the visual domain. It also raises many interesting questions for future research concerning face processing. In Experiment 1, it was confirmed that the haptic system could identify a human face with reasonable accuracy. We are currently investigating whether the neuroanatomical substrate underlying face processing is specific to the visual modality. The neuroanatomicalstructures responsible for visual face processing might also be involved in haptic face processing, or, conversely, neural mechanisms may be limited to the neural structures that typically mediate inanimate haptic object processing.

\section{REFERENCES}

Ballesteros, S., Manga, D., \& Reales, J. M. (1997). Haptic discrimination of bilateral symmetry in 2-dimensional and 3-dimensional unfamiliar displays. Perception \& Psychophysics, 59, 37-50.

Bartlett, J. C., \& Searcy, J. (1993). Inversion and configuration of faces. Cognitive Psychology, 25, 281-316.

Bruce, V., Doyle, T., Dench, N., \& Burton, M. (1991). Remembering facial configurations. Cognition, 38, 109-144.

Bushnell, E. W., \& BAXT, C. (1999). Children's haptic and cross-modal recognition with familiar and unfamiliar objects. Journal of Experimental Psychology: Human Perception \& Performance, 25, 1867-1881.

Clarke, S., Lindemann, A., Maeder, P., Borruat, F.-X., \& Assal, G. (1997). Face recognition and postero-inferior hemispheric lesions. Neuropsychologia, 35, 1555-1563.

Cohen-Levine, S., Banich, M. T., \& Koch-Weser, M. P. (1988). Face recognition: A general or specific right hemisphere capacity? Brain \& Cognition, 8, 303-325.

Cornoldi, C., \& Vecchi, T. (2000). Mental imagery in blind people: The role of passive and active visuospatial processes. In M. A. Heller (Ed.), Touch, representation, and blindness (pp. 143-181). Oxford: Oxford University Press.

DiAmond, R., \& CAREy,S. (1986). Why faces are and are not special: An effect of expertise. Journal of Experimental Psychology: General, 115, 107-117.

Farah, M. J., Wilson, K. D., Drain, M., \& Tanaka, J. N. (1998). What is "special" about face perception? Psychological Review, 105, 482-498.

Heller, M. A., Calcaterra, J. A., Burson, L. L., \& Tyler, L. A. (1996). Tactual picture identification by blind and sighted people: Effects of providing categorical information. Perception \& Psychophysics, 58, 310-323.

Heller, M. A., Calcaterra, J. A., Green, S. L., \& Brown, L. (1999). Intersensory conflict between vision and touch: The response modality dominates when precise, attention-riveting judgments are required. Perception \& Psychophysics, 61, 1384-1398.

Johnson, M. H., Dziurawiex, S., Ellis, H. D., \& Morton, J. (1991). Newborns' preferential tracking of faces and its subsequent decline. Cognition, 40, 1-19.

JoNES, B. (1981). The developmental significance of cross-modal matching. In R. D. Walk \& H. L. Pick Jr. (Eds.), Intersensory perception and sensory integration (pp. 109-136). New York: Plenum.

KAITZ, M. (1992). Recognition of familiar individuals by touch. Physiology \& Behavior, 52, 565-567.

Kaitz, M., Lapidot, P., Bronner, R, \& Eidelman, A. I. (1992). Parturient women can recognize their infants by touch. Developmental Psychology, 28, 35-39.

Kaitz, M., Meirov, H., \& Landman, I. (1993). Infant recognition by tactile cues. Infant Behavior \& Development, 16, 333-341

Kaitz, M., Shiri, S., Danzinger, S., Hershko, Z, \& Eidelman, A. I. (1994). Fathers can also recognize their newborns by touch. Infant Behavior \& Development, 17, 205-207.

KLATzKy, R. L., \& Lederman, S. J. (1987). The intelligent hand. In G. H. Bower (Ed.), The psychology of learning and motivation (Vol. 21, pp. 121-151). New York: Academic Press.

Klatzky, R. L., Lederman, S. J., \& Metzger, V. A. (1985). Identifying objects by touch: An "expert system." Perception \& Psychophysics, 37, 299-302.

Klatzky, R. L., Lederman, S. J., \& Reed, C. (1987). There's more to touch than meets the eye: The salience of object attributes for haptics with and without vision. Journal of Experimental Psychology: General, 116, 356-369.

Klatzky, R. L., Loomis, J. M., Lederman, S. J., Wake, H., \& Fujtta, N. (1993). Haptic identification of objects and their depictions. Perception \& Psychophysics, 54, 170-178. 
Lederman, S. J., \& KLATZKy, R. L. (1987). Hand movements: A window into haptic object recognition. Cognitive Psychology, 19, 342-368.

LEDERMAN, S. J., \& KLATZKY, R. L. (1990). Haptic classification of common objects: Knowledge-driven exploration. Cognitive Psychology, 22, 421-459.

Lederman, S. J., Klatzky, R. L., Chataway, C., \& Summers, C. D. (1990). Visual mediation and the haptic recognition of two-dimensional pictures of common objects. Perception \& Psychophysics, 47, 54-64.

Lederman, S. J., Summers, C., \& Klatzky, R. L. (1996). Cognitive salience of haptic object properties: Role of modality-encoding bias. Perception, 25, 983-998.

Magee, L. E., \& Kennedy, J. M. (1980). Exploring pictures tactually. Nature, 283, 287-288.

MARKs, D. F. (1973). Visual imagery differences in the recall of pictures. British Journal of Psychology, 64, 17-24.

McCarthy, G., Puce, A., Gore, J. C., \& Allison, T. (1997). Face-specific processing in the human fusiform gyrus. Journal of Cognitive Neuroscience, 9, 605-610.

Meltzoff, A. N., \& Borton, R. W. (1979). Intermodal matching by human neonates. Nature, 282, 403-404.

NACHSON, I. (1995). On the modularity of face recognition: The riddle of domain specificity. Journal of Clinical \& Experimental Neuropsychology, 17, 256-275.

Newman, S. E., Sawyer, W. L., Hall, A. D., \& Hill, L. G. J. (1990). Braille learning: One modality is sometimes better than two. Bulletin of the Psychonomic Society, 28, 17-18.

Norton, S. J., Schultz, M. C., Reed, C. M., Braida, L. D., Durlach, N. L., \& Rabinowitz, W. M. (1977). Analytic study of the Tadoma method: Background and preliminary results. Journal of Speech \& Hearing Research, 20, 574-595.

RÉvÉSz, G. (1950). Psychology and art of the blind (H. A. Wolff, Trans.). London: Longmans, Green.

Rhodes, G. (1988). Looking at faces: First-order and second-order features as determinates of facial appearance. Perception, 17, 43-63. Rosch, E., Mervis, C., Gray, W., Johnson, D., \& Boyes-Braem, P. (1976). Basic objects in natural categories. Cognitive Psychology, 8, 382-439.

SERGENT, J. (1984). An investigation into component and configural processes underlying face perception. British Journal of Psychology, 75, 221-242.

TANaKa, J. W., \& Farah, M. J. (1993). Parts and wholes in face recognition. Quarterly Journal of Experimental Psychology, 46A, 225-245.

WALK, R. D., \& PICK, H. L., JR. (1981). Intersensory perception and sensory integration. New York: Plenum.

\section{NOTE}

1. Due to finding $100 \%$ accuracy in a pilot V-V condition, we did not include another condition that we initially thought may be interesting (i.e., a bimodal haptic and visual matching condition, HV-HV). We felt that vision would override haptics in a bimodal task and also result in $100 \%$ accuracy.

(Manuscript received September 13, 2000; revision accepted for publication July 3, 2001.) 